\title{
Theory of Change Model for Clinic-Based PrEP Programme Evaluation
}

Mags Portman ${ }^{1}$, John Saunders ${ }^{1,2}$, Natalyia Brima ${ }^{2}$, Carina King ${ }^{2}$, Nigel Field ${ }^{2}$, Maryam Shahmanesh ${ }^{1,2}$

1. Mortimer Market Centre, Central and North West London NHS Foundation Trust 2. University College London

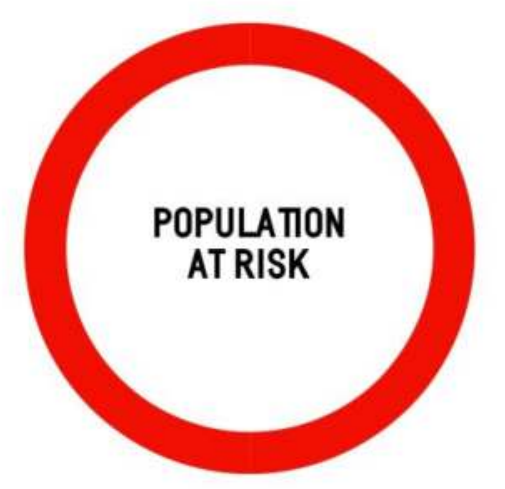

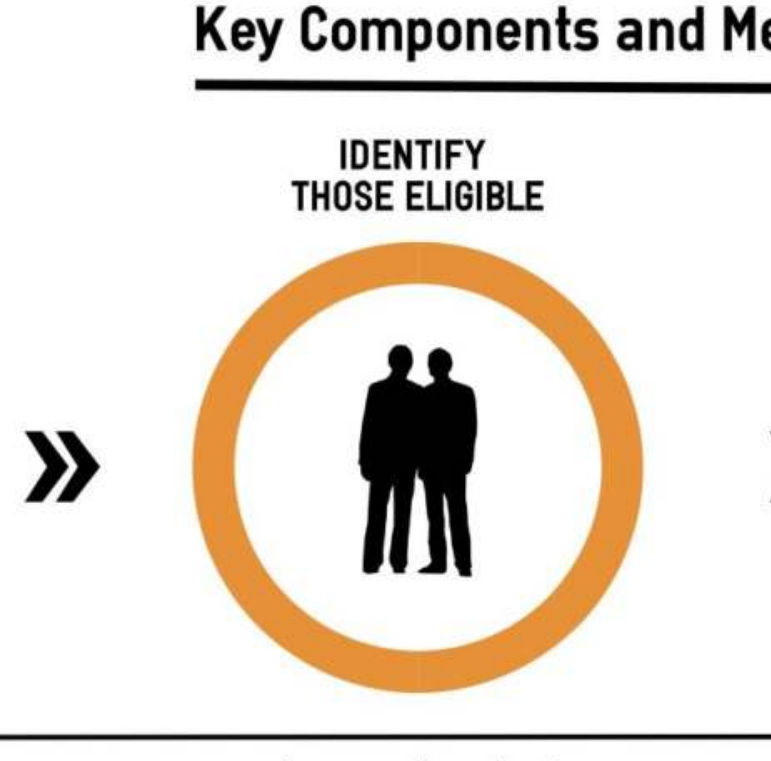

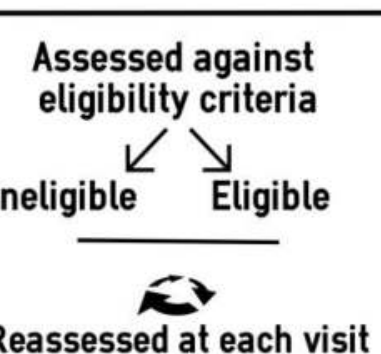

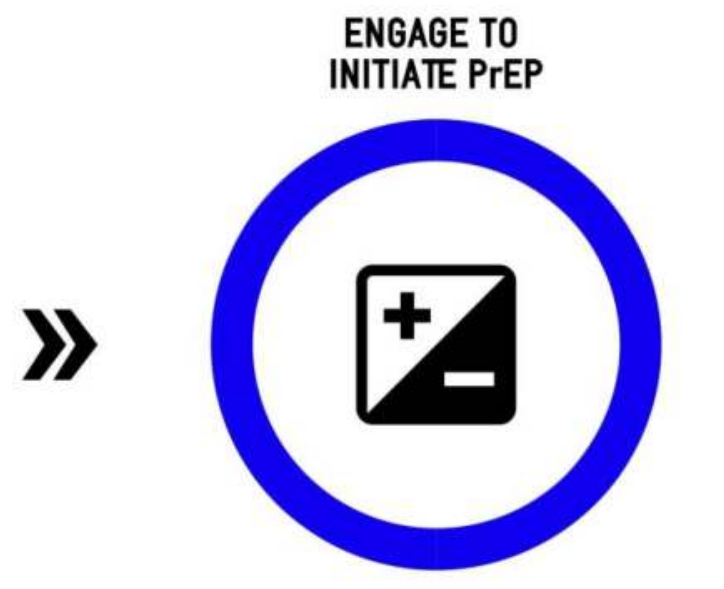

Offer of PrEP alongside good patient information material Declines $\frac{\substack{\searrow \\ \text { Accepts }}}{\text { All offered other key }}$ All offered other key
prevention interventions

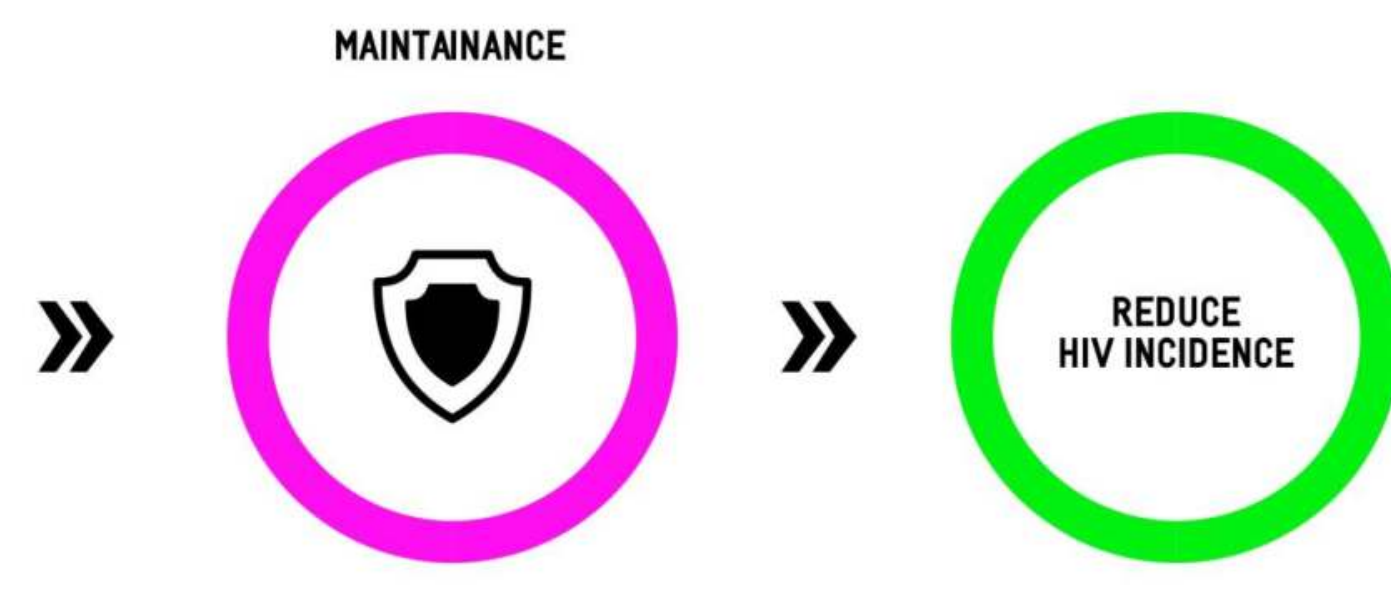

1. PrEP assessment for continued eligibility 2. Adherence discussion 3. HIV \& STI testing

All new HIV diagnoses investigated for missed opportunities

\begin{tabular}{|c|c|c|c|}
\hline $\begin{array}{l}\text { OUTCOME } \\
\text { MEASURES }\end{array}$ & $\begin{array}{l}\text { - \% attendees screened for eligibility } \\
\text { - \% attendees who meet eligibility criteria }\end{array}$ & $\begin{array}{l}\bullet \% \text { eligible who are offered PrEP } \\
\bullet \% \text { offered who accept daily or event based dosing } \\
\text { \% uptake of other prevention interventions }\end{array}$ & 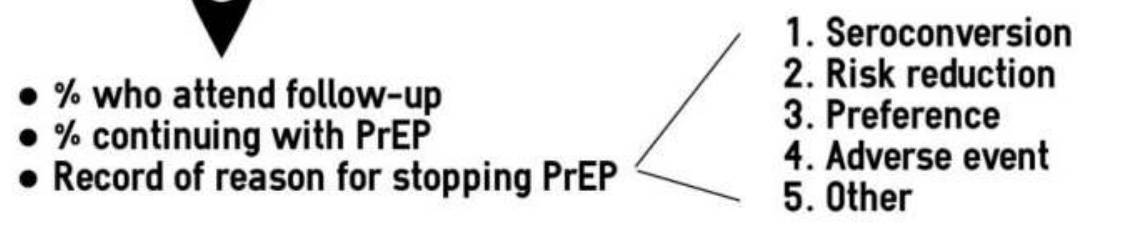 \\
\hline $\begin{array}{l}\text { STRATEGIES } \\
\text { FOR NARROWING } \\
\text { GAPS IN THE } \\
\text { PREP CASCADE }\end{array}$ & $\begin{array}{l}\text { - Community engagement and education } \\
\text { - Routine ascertainment of eligibility criteria } \\
\text { - Self-reported risk factors } \\
\text { - Automatic flags within EPR systems }\end{array}$ & $\begin{array}{l}\text { - Free PrEP and monitoring } \\
\text { - Strong linkage to prevention services } \\
\text { - Peer support }\end{array}$ & $\begin{array}{l}\text { - Simplified clinical and refill pathways } \\
\text { - Adapted adherence support } \\
\text { - Peer support } \\
\text { - Routine (re)enquiry } \\
\text { - Multidisciplinary team meetings to discuss all new seroconversions }\end{array}$ \\
\hline
\end{tabular}

\section{Background:}

- NHS England has agreed to provide £2 million to fund HIV PreExposure Prophylaxis (PrEP) in England over the next two years as part of a test site implementation project

- The process by which this will be implemented and the designated body who has responsibility for on-going PrEP commissioning is still to be decided

- In Scotland, Wales and Northern Ireland, the decision on how PrEP will be funded and implemented is still awaited

- Some MSM already access PrEP either by private prescription in the UK or through obtaining generic tenofovir/ emtricitabine from outside the EU

\section{Some sexual health clinics already offer PrEP monitoring}

\section{Aims:}

- We created a Theory of Change (ToC) PrEP cascade to identify the key components of a clinic-based PrEP programme to reduce HIV incidence

- We identified process, details and outcomes to aid programme evaluation for a large London sexual health clinic

\section{Results:}

The aim of our PrEP programme is to prevent HIV seroconversion and onward transmissions in those at greatest risk.

We identified three broad areas of clinic activity:

1. Identifying those eligible;

2. Engaging eligibles to initiate PrEP and other HIV prevention activities;

3. Maintaining effective adherence in those at continuing risk, while advising therapy cessation for those no longer at risk, plus following up any HIV seroconversions

\section{Conclusion:}

Using a ToC approach we have defined what a clinic-based PrEP programme might look like against our current service specification

- ToC will enable effective planning of PrEP as an intervention in our clinic

- ToC provides us with the indicators we need to evaluate and improve our programme

- This ToC can be used by other clinics to evaluate PrEP programmes, and through existing surveillance systems build our understanding of a national PrEP cascade of prevention 